\title{
MOVIMENTO DE MULHERES CAMPONESAS: 30 ANOS DE HISTÓRIA NA CONSTRUÇÃO DE NOVAS RELAÇÕES
}

Catiane Cinelli*

\begin{abstract}
Resumo
Este artigo visa trazer presente a história de um ator social, o Movimento de Mulheres Camponesas (MMC), que tem em vista a libertação das mulheres de todas as formas de opressão. Pretende-se trazer elementos de como são discutidas e construídas as novas relações no MMC e como este processo contribui para a emancipação das envolvidas. Aborda-se a violência estrutural na sociedade classista e patriarcal, bem como se busca compreender o feminismo e seu papel no interior do movimento. A metodologia utilizada foi a observação participante em atividades do Movimento em Santa Catarina. Percebeu-se que a partir da luta, da organização e da formação, as mulheres camponesas inseridas no MMC desafiam-se a construir novas formas de viver, enfrentando as contradições sociais e vivenciando relações de igualdade, respeito e dignidade.
\end{abstract}

Palavras-chave: Movimento de Mulheres Camponesas. Novas relações. Experiência.

\footnotetext{
* Dirigente do Movimento de Mulheres Camponesas em Santa Catarina. Doutoranda em Educação pela Universidade Federal do Rio Grande do Sul.Email: katimmc@gmail.com
} 


\section{Introdução}

A partir de dados obtidos através da militância da autora no Movimento de Mulheres Camponesas, associada à pesquisa realizada entre 2010 e 2011 e à consulta a documentos do próprio $\mathrm{MMC}$, foi possível a escrita deste texto, que conta metodologicamente com a observação participante e diálogo com as mulheres. A utilização dessas técnicas visou compreender que a prática, tanto vivenciada quanto sistematizada em documentos, é a melhor forma de se analisar uma experiência.

A experiência vivida, segundo Thompson (1981), está associada a determinados modos de vida. Nesse sentido, a experiência vivida como camponesas e militantes do MMC nos permite compreender quais elementos caracterizam a proposta desse Movimento em que estão organizadas as mulheres camponesas. Esta proposta busca a "libertação das mulheres de todo tipo de opressão, na construção do projeto popular de agricultura camponesa, a partir dos princípios da agroecologia e na luta pela transformação da sociedade" (MMC, 2008, p. 5).

As mulheres camponesas militantes do MMC aprendem, estudam, debatem a partir de sua realidade no/do campo. $\mathrm{Ou}$ seja, trazem o seu modo de vida para os espaços de formação no movimento, assim como recebem informações novas com a convivência, experiência e estudos. Tais informações se mesclam entre teoria e prática, sendo que muitos aprendizados desencadeiam novas práticas sociais, seja no espaço privado e público, em meio a crises e avanços. Desta forma, vão transformando seu modo de ser a partir da práxis, de acordo com Paulo Freire (2005).

Foi basicamente no início da década de 1980 que surgiram os principais movimentos camponeses existentes até os dias atuais. Nessa época, a chamada revolução verde se encontrava em processo acelerado, causando consequências e suscitando a organização de movimentos sociais. Algumas bandeiras levantadas reivindicavam a luta pela terra, vida e trabalho, direitos mobilizados pela demanda de uma reforma agrária que nem o reconhecimento da função social da terra, prevista na Constituição de 1988, foi capaz de colocar em prática. Nesse contexto é que as mulheres camponesas iniciam formas específicas de organização para reivindicar direitos, os quais eram negados até então, pois em espaços mistos elas diziam não ser ouvidas (PALUDO, 2009). Em Santa Catarina, no dia $1^{\circ}$ de maio de 1983 , se tem como 
marco o surgimento da Organização das Mulheres Agriculturas

(OMA), a qual três anos depois passa a se denominar Movimento de Mulheres Agricultoras de Santa Catarina (MMA/SC), e, em 2004, este passa a integrar o Movimento de Mulheres Camponesas do Brasil (MMC).

No início da década de 1980 se constata que a organização das mulheres camponesas ocorreu mais por meio de influência de setores progressistas das igrejas, principalmente da Comissão Pastoral da Terra (CPT), do que por influência de outras instituições. Desta forma, as mulheres foram compreendendo o que se passava com elas e se organizaram a partir de suas necessidades. Em falas das mulheres nos espaços de formação, conseguimos perceber o quanto foi importante a organização das mulheres. "A gente como mulher ainda é muito explorada, mas naquela época a gente achava tudo normal" (CINELLI, 2006).

Em “movimento", no então MMA/SC, e com seus processos de formação, organização e lutas, se percebe que a junção de saberes e experiências impõe às mulheres a necessidade de se organizar e se mobilizar para a luta. As mulheres militantes aprenderam - e ainda aprendem - que podem questionar a autoridade masculina expressa pelo pai, pelo marido, ou pelo sogro. Dão-se conta da importância da organização das mulheres e que seu universo pode ser para além da casa, da cozinha e da roça. Questionam, como trabalhadoras e mulheres, as autoridades, as normas e as leis injustas.

No ano de 2004, por ocasião do primeiro congresso nacional do MMC, ocorrido em Brasília entre os dias 05 a 08 de março, vários movimentos autônomos de mulheres, organizados em diferentes regiões do Brasil, se juntaram e consolidaram o MMC em caráter nacional. Com isso, se intensificam discussões sobre a opressão e a exploração do modelo patriarcal adotado pelo capitalismo como estruturante das relações sociais (FARIA, 2012). Insubordinando-se contra esta sociedade patriarcal, as mulheres passam a assumir o feminismo (CONTE; DARON; MARTINS, 2009).

De acordo com Cinelli (2012), as mulheres envolvidas no movimento assumem a formação como uma ação libertadora, que visa a contribuir para serem solidárias umas com as outras, questionando e refletindo, enquanto sujeitos políticos coletivos (RIBEIRO,2010), sobre o seu lugar no mundo, onde são capazes e podem contribuir na construção de uma nova sociedade. Percebe- 
se isso, uma vez que nos processos formativos são escolhidos temas a partir da história de vida das próprias mulheres envolvidas.

Vale ressaltar que a construção de novas relações discutidas pelas mulheres perpassa as discussões de novas formas de contato e trabalho com a natureza, bem como com os seres humanos de modo geral e com os homens, seus companheiros em particular. Essas relações não são trabalhadas apenas em seminários específicos sobre o tema, mas no cotidiano das ações do movimento, que leva a isso. Por se tratar de um movimento específico de mulheres, a questão perpassa todas as discussões e ações que envolvem as militantes, inclusive nas pautas políticas e relações com demais entidades e movimentos sociais mistos, ou seja, constituídos de homens e mulheres.

A partir de outras pesquisas realizadas pela autora (CINELLI, 2006, 2012) conseguimos identificar, a partir de falas das próprias mulheres, que no movimento estas conseguiram se libertar, perderam o medo de falar, começaram a confiar em si mesmas, sentiram-se capazes de transpor as cercas que as oprimiam. Desafiam-se, assim, a cada dia e luta, pois a formação e organização no movimento são compreendidas como um processo integral, o qual não acontece de forma separada das lutas e mobilizações.

Percebemos, também, a partir das observações realizadas, que a vida das mulheres vai se transformando com a participação no movimento. Elas perdem a timidez e o medo de falar em público; ficam mais animadas, afirmam ter mais vontade de viver, deixam de ser submissas aos maridos, não mais obedecendo simplesmente, mas tomando a iniciativa. Passam a participar de locais públicos antes proibidos para mulheres, como câmaras de vereadores(as), consultas sobre determinados problemas às autoridades públicas. Esse movimento de sair do privado para o público modifica a divisão das tarefas na família e elas passam a se valorizar enquanto mulheres, seres pensantes, "donas da própria vida".

Cinelli (2012) identificou que tais mudanças são permeadas por conflitos na maioria das vezes, pois as mulheres passam a romper com padrões sociais, ou seja, com papéis naturalizados e tidos como "normais para as mulheres da roça". De outro lado, sabemos, também, e, como afirmam as mulheres, que não é fácil se manter no movimento, pois, isso exige convicção de que a participação no movimento envolve uma luta contra a sociedade machista patriarcal e capitalista. Sobre a libertação, as mulheres 
afirmam que "Ser liberta é fazer o que nos deixa felizes, ir para onde se tem vontade. Não precisar pedir licença para alguém só porque é homem. Passar a valorizar as mulheres e não aceitar mais piadinhas maldosas sobre elas, que só fortificam o machismo" (CINELLI, 2010).

Questionar as formas de tratamento às mulheres é ação de quem está consciente e se libertando das amarras do patriarcado. Com esse fazer estamos construindo novas relações entre os seres humanos. Temos clareza de que esse processo de transformação é lento, não é simples e unilinear e que tais iniciativas são importantes e necessárias para a construção de um movimento global contra-hegemônico.

\section{A violência do patriarcado e a luta pela libertação}

No patriarcado, de acordo com o MMC (2004), as mulheres passam a ser subjugadas de forma mais intensa, perdem o poder e são relegadas basicamente à esfera doméstica. Desta forma, a sobrecarga de trabalho não reconhecido e não valorizado na grande maioria dos casos ocasiona doenças. O homem, por sua vez, acaba tendo um papel de destaque, centralizando o poder sobre a família. Seu trabalho é considerado produtivo, ao passo que o da mulher não. Às mulheres são delegadas as tarefas de reprodução, que envolvem ter filhos e deles cuidar, bem como da casa, da cozinha, da roupa, logo, ficando a cargo dos homens o comando sobre a maioria dos negócios que envolvem a economia familiar.

No entanto, Muraro (2003) afirma que na sociedade primitiva, o homem pensava que as mulheres pariam seus filhos tendo os deuses por pais. Ressalta ainda que, como as mulheres eram mais prestigiadas naqueles grupos, muitas vezes elas governavam, o que faziam por meio da persuasão e do consenso. Diante disso, fica evidente que as relações sociais e de gênero não são unilineares e tampouco homogêneas.

Segundo Collet (2005), é com o estabelecimento do patriarcado que as relações de poder começam a ser re-configuradas mediante o surgimento da propriedade privada. Para garantir a herança, precisava-se determinar o progenitor, de tal maneira que aos poucos vai-se configurando um modelo de sociedade, no qual o papel dos homens é supervalorizado a partir das figuras do pai e chefe de família. Desta forma, novas relações de desigualdade, de exploração e dominação são estabelecidas entre os gêneros e gerações. 
A partir de tais reflexões é possível afirmar que a exploração e a desvalorização das mulheres têm se configurado de diferentes formas. Acima de tudo, cabe refletir e estudar sobre os fatos do passado para entender e, além disso, perceber como podemos, nos dias atuais, construir formas de (re) empoderamento das mulheres (GEBARA, 2002), tendo em vista as transformações possíveis, já que a sociedade é fruto da ação humana, como já dizia Marx (1998) e outros (as) autores.

$\mathrm{Na}$ história ocorreram vários momentos de rebeldia e contravenções das mulheres, especialmente contra as ações do patriarcado, com maior ou menor intensidade, de forma organizada ou não. Um exemplo disso pode ser identificado a partir da presença das "bruxas" na história da humanidade, que apesar da perseguição e das mortes, organizavam-se em movimentos considerados heréticos, como por exemplo, os cátaros, segundo Muraro (1992). De acordo com a mesma autora, o cristianismo foi uma das bases contribuidoras para o patriarcalismo. $\mathrm{O}$ deus único e macho, e a imagem das mulheres vinculadas a Eva, pecadora e culpada pela fraqueza dos homens, perpassam concepções e práticas consideradas oficiais, segundo um livro sagrado, que teria sido inspirado por "Deus". Desta forma, escritos bíblicos, em vários trechos, trazem a desvalorização da mulher e sua condição "natural" de inferioridade (MURARO, 1992).

Na primeira carta de São Paulo aos Coríntios, por exemplo, afirma-se que a cabeça da mulher é o homem, por isso as mulheres precisam rezar com o véu na cabeça, pois esse é o sinal de sua dependência. Outros documentos presentes na história da Igreja, que explicitam a subordinação da mulher ao homem, muito utilizados em cerimônias de casamento, são as cartas desse mesmo apóstolo, que afirmam que as mulheres devem ser submissas a seus maridos (BÍBLIA SAGRADA, 1990). Se de um lado conseguimos fazer a crítica, inclusive por atuarmos em movimento específico de mulheres, de caráter feminista, de outro sabe-se que há uma grande parcela de mulheres que acredita ser inferior e nascida de uma costela de Adão. Tal representação foi construída a partir de elementos religiosos conservadores e discriminatórios presentes principalmente na cultura ocidental e transmitidos de geração a geração, demonstrando a importância da luta feminista na desconstrução desses princípios e dogmas, tendo em vista a libertação das mulheres. 
Nesse sentido, cabe a reflexão de que trabalhar e lutar cotidianamente por avanços nas questões de gênero tem a ver com a possibilidade de construir outros valores familiares ou grupais para as demais gerações, pois, se o movimento conseguiu alguns avanços, foi devido a muitas lutadoras (es) que enfrentaram o patriarcado antes de nossa geração. Neste aspecto, olhar para a história e projetá-la, mesmo que de forma utópica, nos ajuda a perseguir um horizonte de maior igualdade, já que existem indícios de que tenham existido sociedades de parceria (EISLER, 1996).

Em outra obra,Muraro (2003) descreve que a espécie humana tem, aproximadamente, dois milhões de anos de existência. Nos primeiros um milhão novecentos e noventa mil anos, não havia a supremacia masculina, tão conhecida hoje. Eram os princípios masculinos e femininos que governavam juntos o mundo. Consideramos de fundamental importância o que nos apresenta a autora, pois, o que nos é mostrado, na história é a supremacia masculina, inclusive com poucos questionamentos sobre ela.

Castells (1999) afirma que a família patriarcal, base fundamental do patriarcalismo, vem sendo contestada pelos processos inseparáveis de transformação do trabalho feminino e de conscientização da mulher. As forças propulsoras desses processos são o crescimento de uma economia informal global, as mudanças tecnológicas no processo de reprodução da espécie, e o impulso poderoso promovido pelas lutas das mulheres e por um movimento feminista multifacetado.

Segundo o mesmo autor, as mulheres, por ocuparem o mercado de trabalho e serem remuneradas, deixam de ser dependentes economicamente dos maridos. Por outro lado, destaca o peso colocado sobre os ombros das mulheres, que chegam a assumir quádruplas jornadas diárias (trabalho remunerado, organização do lar, criação dos filhos e a jornada noturna em benefício do marido) (CASTELLS, 1999). Da mesma forma, no campo, além das mulheres sofrerem as consequências do modelo capitalista de agricultura, também enfrentam a cultura patriarcal que se revela de muitas maneiras.

Castells afirma que uma das maneiras se revela através da dominação machista, a partir da qual as mulheres têm pouca participação nas decisões, pois ainda permanece a opinião do pai, quando solteiras, e do marido, depois de casadas. Isso é evidente no ato de investir os recursos na propriedade. Outra situação é na 
distribuição da herança, onde o filho homem normalmente fica com a terra ou com uma parte maior. Nos momentos de lazer isso também fica evidente, na medida em que os filhos homens sempre têm mais acesso e liberdade do que as filhas mulheres em relação aos rendimentos obtidos pela família e centralizados pelo pai. A partir dessas observações, constatamos que em relação à questão do acesso a terra, as mulheres já têm conseguido conquistar a titulação conjunta da propriedade e inserir o nome no bloco como produtora rural. Essas situações configuram-se em rearranjos que fogem à regra.

Segundo Brumer (2007), apesar de a mulher trabalhar o dia todo na agricultura e ainda fazer todo o trabalho doméstico, ela é vista como ajudante do homem, sendo que todos os afazeres domésticos não são considerados trabalho, e sim serviço. No senso comum, como as mulheres "nasceram para servir, isto é tarefa delas", algo que o MMC desde seu surgimento busca questionar e intervir por meio de seus processos formativos, em que as mulheres vão construindo percepções mais alargadas de seus universos.

Devido à inferioridade atribuída às mulheres na sociedade patriarcal, seus trabalhos são, da mesma forma, inferiorizados, o que é uma forma de violência contra elas. Gebara (2002) argumenta que a estrutura básica da sociedade em que vivemos é violenta e, ao mesmo tempo, violentadora das mulheres e crianças pobres. Inclusive, muitas formas de violência passam a ser quase que naturalizadas e não mais percebidas. Para ilustrar, trazemos uma reflexão do próprio movimento:

Em se tratando da família: afirmar e querer que a responsabilidade de cuidar das crianças, dos doentes, dos idosos, seja só da mulher, quando deveria ser uma responsabilidade de todos, é violência. Quando na família, o homem busca se apossar do dinheiro, decidindo sozinho onde será aplicado, ao invés de todos os membros da família participar (sic) do resultado da produção, que é fruto do trabalho de todos, também é violência. $\mathrm{O}$ homem sair de casa na hora que bem entender e a mulher sair de casa somente quando tiver todo o trabalho organizado, pronto. $\mathrm{Na}$ relação sexual entre o casal, a mulher ser forçada sem desejar esta relação e nem sentir nenhum prazer, são situações e práticas de violência (MMA/SC, 2004, p. 3).

Em muitos casos, em nossos cotidianos ainda experienciamos fatos em que, quando um homem fala, sua palavra é considerada, valorizada, "tem crédito". Quando se trata de uma mulher, 
tantas vezes sua palavra passa invisibilizada, ou é apropriada por um homem, e desta forma acaba sendo reconhecida e tendo importância. Este e tantos outros casos fazem parte de um círculo de violência patriarcal, das quais muitas passam despercebidas por grande parcela da população. Diante disso, poderíamos concluir que não há como se referir a novas relações sem "mexer" na estrutura da sociedade violenta, que vitima de modo especial as mulheres, acima de tudo, indígenas, negras e as mais empobrecidas. Não há como falar em um mundo melhor até que seja condenado qualquer ato de diminuição e proibição das mulheres serem sujeitos de suas falas e de suas ações, de serem mais, no sentido freireano apresentado na obra "Pedagogia do Oprimido" (FREIRE, 2005).

Entendemos que a igualdade se constrói a partir do respeito pelas diferenças, entre homens e mulheres de diferentes etnias, classes sociais, faixas etárias, religiões. Neste sentido, a autonomia das mulheres não se configura somente em relação aos homens, na medida em que constitui condição indispensável para o combate contra ao machismo, a violência sexista e qualquer tipo de intolerância.

As dependências afetiva e financeira fragilizam mais as mulheres, vitimizando-as diante da violência. Isso não significa afirmar que quem está em um processo de libertação ou na luta coletiva pela emancipação já superou todas essas formas de violência, na medida em que existem contradições na própria luta e vivências das mulheres.

É no sentido da luta e prática pela libertação da mulher que se justifica a organização de movimentos de mulheres, necessária na construção de novas relações entre os seres humanos e, no mundo atual, sabemos que esse fazer é indispensável para o futuro da espécie humana.

\section{Considerações Finais}

Constatamos que os 30 anos de história e organização do Movimento de Mulheres Camponesas em Santa Catarina, entre 1983 a 2013, foram marcados por momentos de estudos, passeatas, mobilizações e de enfrentamento à estrutura desigual da sociedade. Essa caminhada em busca da libertação das mulheres e do povo oprimido nos parece essencial.

Percebemos que "o sair de casa" foi a primeira e principal conquista do MMC, na medida em que esta possibilidade nem 
sempre esteve garantida, fato corriqueiro em uma sociedade onde grande parte dos homens sente-se donos das mulheres. Os enfrentamentos ao patriarcado precisam ser feitos cotidianamente em vista da chamada reapropriação de poder, parafraseando Gebara (2002).

Nas várias observações realizadas, decorrentes do fato de vivenciarmos muitas situações e experiências no $\mathrm{MMC}$, podemos ressaltar que as mulheres militantes, cada vez mais se dão conta de que precisam estar se construindo enquanto sujeitos políticos coletivos de todas as ações do movimento, desde pensar e estrategiar a formação política até os rumos do movimento. $\mathrm{Na}$ medida em que vivenciam processos de formação e luta mesmo que a partir de contradições e conflitos, as mulheres camponesas vão ampliando suas visões de mundo.

Compreende-se que as contradições vividas no/pelo movimento, não ocorrem por acaso, mas, pelo fato de vivermos em uma sociedade patriarcal, onde as mulheres são tidas como "dóceis e frágeis", apaziguadoras e jamais como pessoas que enfrentam conflitos e desafiam o sistema. Em geral, todas as formas de contestações são rechaçadas e, quando partem de mulheres, e, em particular, de mulheres camponesas, são mais estereotipadas ainda. Mas, devido a isso, com a força proporcionada pelo movimento, aprendem a superar e continuar em luta por questões mais amplas, como elas mesmas se referem, almejando uma sociedade liberta, sem violência e opressão sobre as mulheres, sobre o planeta como um todo.

Podemos afirmar que a concepção de formação do MMC segue os princípios da educação popular, sendo esta baseada na realidade vivida pelas mulheres e na história dos demais sujeitos envolvidos no movimento. Acima de tudo, as falas das mulheres mostram que elas aprendem com a participação no movimento, o que nos leva a concluir que estão se construindo passos rumo à libertação, forçando transformações desde o ambiente em que vivem e, possibilitando que as novas gerações possam pensar um pouco diferente, onde homens e mulheres, jovens e adultos, possam vivenciar novas relações de gênero.

Neste sentido, podemos afirmar que a formação e a luta presente no MMC, contribuem para a libertação de mulheres e homens, e consequentemente, para a não violência, pois se trata de uma concepção de formação humana que forma para a vida, levando a consciência de que um novo mundo é possível 
e necessário. $\mathrm{Na}$ concepção do movimento, a construção do socialismo se dará com o feminismo, ou seja, com a participação efetiva das mulheres.

As mulheres são mais da metade da população que não aceita mais ficar calada diante da violência e vêm abrindo espaços em terrenos considerados inicialmente masculinos. A discussão da libertação da mulher é a oportunidade de mulheres e homens criarem um novo pacto absolutamente essencial para a sobrevivência da própria espécie (GEBARA, 2002).

Finalmente, entendemos que para mudar as próprias condições de produção das relações de exploração e de dominação é necessário todo um processo coletivo de mudanças de paradigmas. Acredita-se que, aos poucos, mesmo que lentamente, muitas mulheres em diversos movimentos têm incidido sobre as práticas cotidianas e, desta forma, na cultura. Consideramos importante cultivar sempre a dialética das relações entre mulher e homem, tendo em vista que a vida humana se desenvolve na interação contínua entre os dois sexos, apesar das injustiças históricas que sofremos.

\section{Referências Bibliográficas}

BÍBLIA SAGRADA. Brasília, Edições Paulinas, 1990.

BRUMER, Anita. Gênero e Agricultura: a situação da mulher na Agricultura do Rio Grande do Sul. Revista Estudos Feministas. Florianópolis, 2007. V. 12, n. 1, p. 205-227.

CASTELLS, Manuel. O poder da identidade. São Paulo, Paz e Terra, 2002.

CINELLI, Catiane. A Educação Popular e as novas relações de gênero no Movimento de Mulheres Camponesas de Santa Catarina. In: IV Encontro Rede de Estudos Rurais, 2010, Curitiba. IV Encontro da Rede de Estudos Rurais: Mundo rural, políticas públicas, instituições e atores em reconhecimento político. Curitiba: Rede de Estudos Rurais - UFPR, 2010.

Mulheres em formação no Movimento de Mulheres Camponesas em Santa Catarina. Veranópolis, 2006. (Trabalho de Conclusão do Curso de Pedagogia). Universidade do Estado do Rio Grande do Sul, Veranópolis, 2006. 
CINELLI, Catiane. Programa de sementes crioulas de hortaliças: experiência e identidades no Movimento de Mulheres Camponesas, 2012.113p. (Dissertação de Mestrado).Universidade Regional do Noroeste do Estado do Rio Grande do Sul, Ijuí, 2012.

CONTE, Isaura Isabel; DARON, Vanderléia Pulga; MARTINS, Mariane Denise. Movimento de Mulheres Camponesas: na luta a constituição de uma identidade feminista, popular e camponês. In: PALUDO, Conceição (org.) Mulheres, resistência e luta: em defesa da vida. São Leopoldo: CEBI, 2009.

EISLER, Raiane. O prazer sagrado: sexo, mito e política do corpo. Tradução de Ana Luiza Dantas Borges. Rio de Janeiro: Rocco, 1996.

FARIA, Lia. Feminismo e transformação social. Cadernos Sempreviva. São Paulo: Ed. SOF Sempreviva Organização Feminista, p. 06 - 15, 2012.

FREIRE, Paulo. Pedagogia do Oprimido. Rio de Janeiro: Paz e Terra, 2005.

GEBARA, Ivone. Cultura e relações de gênero. Seminário do Cepis. São Paulo. Instituto Cajamar, 2002.

MARX, Karl. O Capital. Crítica da Economia Política. Livro 1. V. 1. 16 ed. Rio de Janeiro: Civilização Brasileira, 1998.

MOVIMENTO DE MULHERES AGRICULTORAS DE SANTA CATARINA. Nossa história, nossas lutas. Chapecó, SC, MMA/SC, 2000.

MOVIMENTO DE MULHERES CAMPONESAS. Plantando saúde pelos caminhos do RS. MMC/RS, 2004.

MURARO, Rose Marie. Um mundo novo em gestação. Campinas; São Paulo, Versus, 2003.

Tempos, 1992.

A mulher no terceiro milênio. 2 ed. Rio de Janeiro, Rosa dos

PALUDO, Conceição (Org.) Mulheres, resistência e luta: em defesa da vida. São Leopoldo: CEBI, 2009.

.Educação popular em busca de alternativas. Uma leitura desde o campo democrático popular. Porto Alegre: Tomo Editorial, 2001. 
RIBEIRO, Marlene. Movimento camponês, trabalho, educação.

Liberdade, autonomia, emancipação como princípios/fins da formação

humana. São Paulo: Expressão Popular, 2010.

THOMPSON, Edward P. A miséria da teoria ou um planetário de erros (Uma crítica ao pensamento de Althusser). Rio de Janeiro: Zahar

Editores, 1981.

\title{
PEASANT WOMEN MOVEMENT:THIRTYYEARS OF HISTORY BUILDING NEW RELATIONSHIPS
}

\begin{abstract}
This article aims at bringing up the history of a social actor, the Peasant Women Movement (MMC), which claims for women's liberation from all kinds of oppression. It is intend to bring elements of how is debated and built the new relationships in the MMC and how this process contributes to the emancipation of its participants. It addresses the structural violence in a classist and patriarchal society as well searches to comprehend the feminism and its rule inside the movement. The methodology used participant observation regarding their actions in of the Movement Santa Catarina state. It was verified that since the beginning of the struggle, organization and formation, the peasant women in the $\mathrm{MMC}$ were challenged to create new ways of living, facing the social contradictions as well experiencing equalitarian, respectful and dignified relationships.
\end{abstract}

Keywords: Peasant Women Movement. New Relationships. Experience. 